\title{
Protection against Experimental Melioidosis with a Synthetic manno- Heptopyranose Hexasaccharide Glycoconjugate
}

\author{
Andrew E. Scott, ${ }^{*},{ }^{\dagger}, \#$ William J. Christ, ${ }^{*}, \#$ Alison J. George, ${ }^{\dagger}$ Margaret G. M. Stokes, ${ }^{\dagger}$
}

Gregory J. S. Lohman, ${ }^{\ddagger}$ Yuhong Guo, ${ }^{\ddagger}$ Matthew Jones, ${ }^{\ddagger}$ Richard W. Titball, ${ }^{\S}$ Timothy P. Atkins, ${ }^{\dagger}$

A. Stewart Campbell, ${ }^{\dagger, \triangle}$ and Joann L. Prior ${ }^{\dagger, \triangle}$

${ }^{\dagger}$ Defence Science and Technology Laboratory, Porton Down, Salisbury, Wiltshire SP4 0JQ United Kingdom

"Corden Pharma International Inc. (formerly Ancora Pharmaceuticals Inc.), Woburn, Massachusetts 01801 United States

${ }^{\S}$ College of Life and Environmental Sciences, University of Exeter, Exeter, Devon EX4 4QD, United Kingdom

Supporting Information

ABSTRACT: Melioidosis is an emerging infectious disease caused by Burkholderia pseudomallei and is associated with high morbidity and mortality rates in endemic areas. Antibiotic treatment is protracted and not always successful; even with appropriate therapy, up to $40 \%$ of individuals presenting with melioidosis in Thailand succumb to infection. In these circumstances, an effective vaccine has the potential to have a dramatic impact on both the scale and the severity of disease. Currently, no vaccines are licensed for human use. A leading vaccine candidate is the capsular polysaccharide consisting of a homopolymer of unbranched $1 \rightarrow 3$ linked 2-O-acetyl-6-deoxy- $\beta$ D-manno-heptopyranose. Here, we present the chemical synthesis of this challenging antigen using a novel modular disaccharide assembly approach. The resulting hexasaccharide was coupled to the nontoxic $\mathrm{H}_{c}$ domain of tetanus toxin as a carrier protein to promote recruitment of T-cell help and provide a scaffold for antigen display. Mice immunized with the glycoconjugate developed IgM and IgG responses capable of recognizing native capsule, and were protected against infection with over $120 \times \mathrm{LD}_{50}$ of B. pseudomallei strain K96243. This is the first report of the chemical synthesis of an immunologically relevant and protective hexasaccharide fragment of the capsular polysaccharide of $B$. pseudomallei and serves as the rational starting point for the development of an effective licensed vaccine for this emerging infectious disease.

\section{INTRODUCTION}

Melioidosis is a serious and often fatal disease caused by the Gram negative, facultative intracellular pathogen Burkholderia pseudomallei. ${ }^{1}$ The disease is prevalent in South-East Asia and Northern Australia, although the area of endemicity is expanding rapidly as surveillance improves and cases are described in other countries (ref 2; see www.melioidosis.info for up-to-date global distribution). The clinical presentation of melioidosis is varied, ranging from localized infections and abscess formation through to acute pulmonary infections and fulminating septicaemias. ${ }^{3,4}$ Antibiotic therapies are available for melioidosis, typically requiring several weeks of intravenous administration followed by orally delivered antibiotics which may last several months. ${ }^{5}$ Overall mortality in individuals presenting with melioidosis at medical facilities varies by country ( $\sim 40 \%$ in Thailand, $\sim 15 \%$ in Australia), but mortality can be up to $90 \%$ with septicaemic melioidosis, even with appropriate antibiotic therapy. ${ }^{4,6,7}$ Due to the nonspecific presentation, the rapid course of disease, the intrinsic resistance of B. pseudomallei to commonly used antibiotics, and the risk posed by aerosolized bacteria if deliberately released, $B$. pseudomallei is currently classified as a CDC Tier 1 Select Agent under 42 CFR Part 73 (see http://www.selectagents. gov/).

At present there is no licensed vaccine to protect against melioidosis. Considerable work has been undertaken to identify and develop vaccine candidates which will protect humans against melioidosis (for recent reviews, see refs 8-10). From these studies, the manno-heptopyranose capsular polysaccharide (CPS) has emerged as a leading candidate. This polysaccharide is a homopolymer of unbranched $1 \rightarrow 3$ linked 2 -O-acetyl-6-deoxy- $\beta$-D-manno-heptopyranose ${ }^{11,12}$ and is a major virulence determinant in $B$. pseudomallei. ${ }^{13,14}$ Interestingly, B. pseudomallei appears to express only this single serotype of capsule and it is present in all reported isolates; the same is true for all isolates of the related pathogen Burkholderia mallei, the causative agent of glanders. ${ }^{15} \mathrm{~A}$ capsule-based vaccine would therefore potentially offer cross-species

Received: September 27, 2015

Revised: March 6, 2016

Published: April 28, 2016 
protection against both pathogens. Recent work has demonstrated that CPS purified from B. pseudomallei induces protective immunity against experimentally induced melioidosis in mice ${ }^{16}$ and that immune responses and protection can be significantly improved through conjugation of the polysaccharide to a carrier protein. ${ }^{17,18}$ However, current methodology requires that CPS is purified from bacteria in containment (at least BioSafety Level 2), a manufacturing process which is both technically demanding and expensive, and may not readily translate to commercial scale manufacturing. Moreover, the purified native CPS also displays heterogeneity of chain length and may contain copurified endotoxin or other polysaccharides, ${ }^{19}$ introducing complications to analysis, handling, and quality control. A synthetic source of CPS wherein all structural features of the antigen are unequivocally defined and established chemical manufacturing infrastructure could be utilized would be more appropriate as a choice for the antigen in a CPS-based vaccine.

The B. pseudomallei/mallei CPS presents a variety of structural aspects that render it a challenging target for chemical synthesis. Specifically, $\beta$-mannoside linkages are traditionally problematical ${ }^{20}$ and the presence of the onecarbon chain-extension at the pyranose C- 6 precludes standard implementation of approaches to $\beta$-mannosides using 4,6benzylidene protected donors developed by the Crich group ${ }^{20}$ and adapted by others. ${ }^{21,22}$ Furthermore, the presence of the potentially labile and migration prone $2-O$-acetyl group on each residue necessitates a highly engineered protecting group strategy; this group has been shown to be necessary for antigen recognition by monoclonal antibodies, ${ }^{23}$ although whether this is relevant to protective immunity has not been examined. A recent study has detailed an elegant approach to the synthesis of a protected $\beta$-(1,3)-linked manno-heptopyranose disaccharide $^{24}$ utilizing installation of the C-6 one-carbon chain extension at the monosaccharide stage and chain extension via intramolecular aglycon delivery. However, this work did not extend the glycan chain past the disaccharide stage or investigate whether this disaccharide could induce protective immune responses.

This work describes a novel approach to the chemical synthesis of a $1 \rightarrow 3$ linked 2 -O-acetyl-6-deoxy- $\beta$-D-mannoheptopyranose hexasaccharide using a modular disaccharide assembly approach. This hexasaccharide was covalently linked to a recombinant carrier protein to improve immunogenicity and the resulting glycoconjugate shown to stimulate production of antibodies specific for native CPS and to confer significant protection in mice following a challenge with a lethal dose of $B$. pseudomallei.

\section{RESULTS AND DISCUSSION}

Retrosynthetic Analysis of Capsular Antigen Target 1. Synthetic hexameric capsular polysaccharide antigen 1 ( ${ }_{\mathrm{SH}} \mathrm{CPS}$ ) was designed to incorporate all of the distinguishing structural features of the natural polysaccharide in addition to a reducing end linker moiety that would allow for directed conjugation to a carrier protein (Figure 1). The choice of a hexasaccharide versus a target of different length would simultaneously provide a size likely to be immunologically relevant, ${ }^{25,26}$ although the minimum protective epitope for this antigen is not currently known, and would provide a vehicle for development of an efficient modular assembly approach for the synthesis of antigens and fragments featuring an even number of repeating heptosides. In designing the synthesis there was a need to
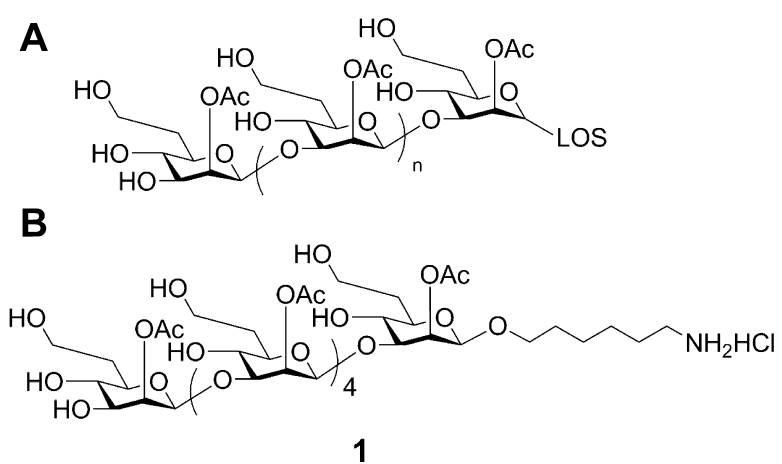

Figure 1. Manno-heptopyranose antigens in this study. (A) Structure of natural capsular polysaccharide from B. pseudomallei. In this rendering the polysaccharide is anchored to a lipooligosaccharide (LOS) at the reducing end, although it should be noted that the molecule to which the capsule is anchored is not currently known. (B) Structure of synthetic hexameric capsular polysaccharide target antigen 1.

identify assembly and final deblock sequences that minimized manipulation and complex chemical operations on large, potentially sensitive synthetic intermediates. In an effort to identify an efficient route with a high probability of success, many strategies were considered, including: (i) assembly of a $\beta$ mannopyranose oligosaccharide framework followed by installation of the C-6 one-carbon chain extension on each monosaccharide residue either sequentially or en masse. While this approach would allow implementation of the proven $\beta$ mannoside synthesis methodology, ${ }^{20}$ it would require six multistep C-6 homologations during assembly; (ii) installation of the C- 6 one-carbon chain extension at the monosaccharide building block stage, followed by assembly of a poly- $\beta$-D-glucoheptopyranose hexasaccharide and performing six inversions at the $\mathrm{C}-2$ position of each residue to establish the desired $\beta$-Dmanno-heptose stereochemistry. This option would require significant late stage manipulation of a fully assembled hexasaccharide and would rely on the C-2 position in every monosaccharide residue being sterically accessible for inversion; (iii) installation of the C- 6 one-carbon chain extension at the monosaccharide stage but assemble the hexasaccharide backbone via intramolecular aglycon delivery. ${ }^{27}$ Indeed, this approach has recently been described for the synthesis of a protected $\beta$-(1,3)-linked manno-heptopyranose disaccharide. ${ }^{24}$ The reservations with this strategy, however, were the uncertainty of the efficiency of this methodology for assembling larger oligosaccharides and the considerable manipulation that would be required on valuable advanced synthetic intermediates. Recent publications during the completion of this work have indeed demonstrated the successful implementation of intramolecular aglycon delivery for assembly of large oligosaccharides; $^{28,29}$ therefore, intramolecular aglycon delivery represents a potential alternative approach to oligosaccharides such as (1).

Thus, the initial strategy was centered on option (ii) using a C-6 homologated gluco-configured monosaccharide building block, which was to be used for iterative coupling to form $\beta$ gluco-heptopyranose linkages during assembly. In this case, inversion at $\mathrm{C}-2$ of the nonreducing end residue would be performed at each assembly iteration to yield the desired $\beta$ manno configuration. Such a strategy, based on a C-2 ketodonor followed by postcoupling reduction, was implemented successfully for the construction of a C. albicans derived poly- $\beta$ - 
mannoside ${ }^{30}$ based on the pioneering work by Lichtenthaler. ${ }^{31}$ More recently, a postcoupling C-2 inversion approach via C-2 triflate ester displacement by azide was utlilized to achieve the $\beta$-D-ManNAcA configuration en route to the synthesis of the repeating unit of the $S$. aureus type 5 capsular polysaccharide. ${ }^{32}$ While this approach circumvents the challenges associated with multiple late-stage inversion transformations, and indeed was successful for smaller oligosaccharides, the significant amount of manipulation required on larger structures was a major concern. As a result, modest re-engineering of the strategy allowed implementation of a modular disaccharide assembly approach using key disaccharide building block 2 (Figure 2),

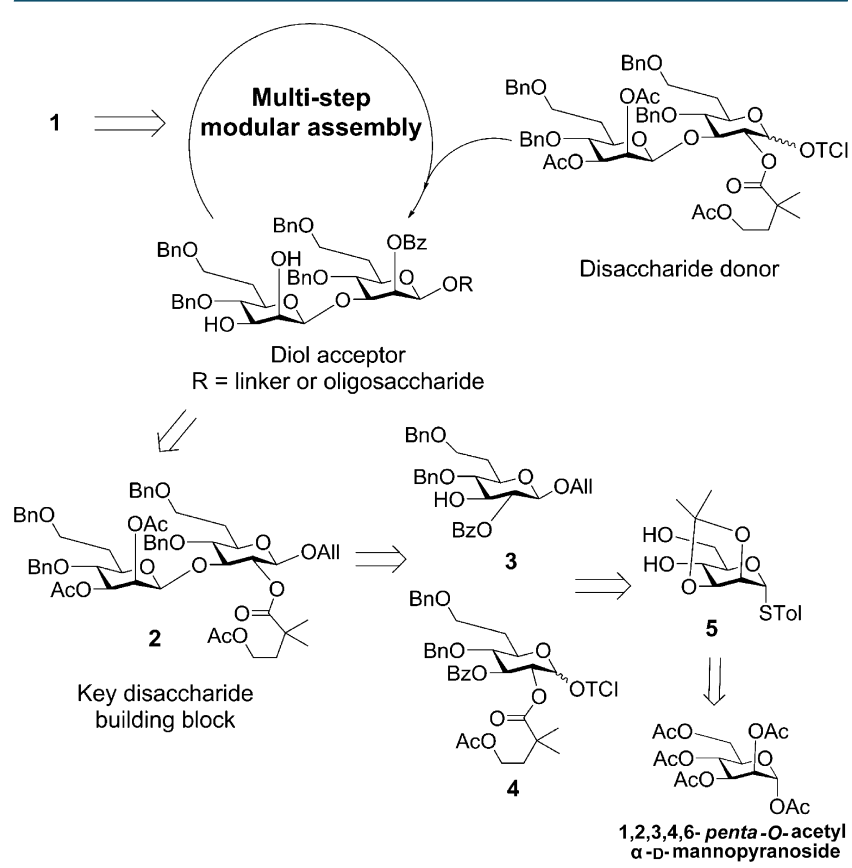

Figure 2. Retrosynthetic analysis of manno-heptopyranose capsular antigen target 1 . Synthetic strategy to allow modular assembly of the $1 \rightarrow 3$ linked 2-O-acetyl-6-deoxy- $\beta$-D-manno-heptopyranose hexasaccharide target antigen $\mathbf{1}$.

which was amenable to large-scale preparation from a single monosaccharide building block 5 and had the majority of the required stereochemistry and functionality already built in. Specifically, building block 2 incorporated the requisite C-6 chain extensions and a $\beta$-manno-heptose linkage between the two monosaccharide residues. The reducing end gluco-heptose residue, which served as the donor group during assembly, was fitted at C-2 with the 4-acetoxy-2,2-dimethyl butanoyl (ADMB) ester, ${ }^{33}$ a participating ester group to control the glycosylation stereochemistry, minimize the potential for orthoester formation during assembly, and enable regioselective liberation of the C-2 hydroxyl for subsequent inversion to the $\beta$-manno configuration. Benzoyl esters were also considered, but benzoates were envisaged as protecting groups for the manno-C-2 positions in the growing chain to allow late-stage installation of the critical 2-O-acetates in the final structure. The protecting group for the manno-C-3 position required facile and selective removal to liberate the 3-hydroxyl as the acceptor for the next assembly cycle. Many protecting groups with reactivity orthogonal to that of the benzoyl and $\mathrm{ADMB}$ esters were evaluated in scouting studies, but it was concluded that the use of $\mathrm{O}$-acetates for both manno-C-3 and manno-C-2 would be the most reliable and, if necessary, would accommodate multiple approaches throughout assembly. Specifically, exploiting wellestablished regioselective coupling to the 3-position of a 2,3diol mannose acceptor ${ }^{34}$ would streamline assembly; however, if the selectivity proved unacceptable or made subsequent analysis too difficult, the option remained to use 2,3orthobenzoate formation followed by regioselective opening to the 2-O-benzoyl leaving the 3-hydroxyl open as the only possible acceptor. This strategy ultimately proved successful as it minimized the amount of manipulation of larger intermediate structures and enabled the development of a standard protocol for each iterative cycle during assembly. Use of benzyl ethers as stable protecting groups for the C-4 and C-7 hydroxyls and benzyl protecting groups for the linker nitrogen would set the stage for a final global deprotection step.

Building Block Synthesis. The monosaccharide building blocks 3 and 4 en route to key disaccharide 2 were prepared from a common glycal intermediate 7 (Figure 3), which is available in seven steps from the known mannose derivative 5. $^{35,36}$ Elaboration of 7 to the common advanced intermediate 8 was achieved in seven steps with $65 \%$ overall yield by first installing the $p$-methoxybenzyl (PMB) ether at C-3 followed by osmium-catalyzed dihydroxylation of the $\beta$-face of the glycal. Subsequent acetylation, selective removal of the anomeric acetate using benzylamine, trichloroacetimidate formation, installation of the allyl glycoside, and final removal of the 2$\mathrm{O}$-acetyl group completed the formation of 8 . The stereochemistry of intermediate $\mathbf{8}$ was verified using a combination of 1-D and 2-D nuclear magnetic resonance (NMR) spectroscopy. From $2-\mathrm{D}{ }^{1} \mathrm{H}-{ }^{13} \mathrm{C}$ correlation (HSQC) experiments the $\mathrm{H}-1$ signal was identified as a doublet $\left({ }^{3} J_{\mathrm{H} 1 \mathrm{H} 2}=7.3 \mathrm{~Hz}\right)$ at $4.31 \mathrm{ppm}$ due to its correlation to the anomeric ${ }^{13} \mathrm{C}$ signal at $101.73 \mathrm{ppm}$. From this assignment the ring $\mathrm{H}-2 \mathrm{H}-3$ and $\mathrm{H}-4$ ring protons were easily identified from the COSY spectrum $(\mathrm{H}-2: 3.63 \mathrm{ppm}$, dd, ${ }^{3} J=9.1,7.3 \mathrm{~Hz} ; \mathrm{H}-3: 3.33$ ppm, t, ${ }^{3} J=9.1 \mathrm{~Hz} ; \mathrm{H}-4,3.53$ ppm, $\mathrm{t},{ }^{3} \mathrm{~J}=9.1 \mathrm{~Hz}$ ). Taken together, these coupling constants are consistent with an all-trans-equatorial pyranose ring, i.e., $\beta$ gluco configured. With the structure of $\mathbf{8}$ firmly established and material available in significant quantity, it was split and transformed in parallel to monosaccharides $\mathbf{3}$ and $\mathbf{4}$ as follows. Benzoylation at C-2 of intermediate 8 using benzoyl chloride in pyridine in the presence of DMAP followed by cerium(IV) ammonium nitrate-mediated cleavage of the 3-O-PMB ether gave 3 in $96 \%$ overall yield. In parallel, donor 4 was produced by installing an $\mathrm{ADMB}$ ester at $\mathrm{C}-2$ of $\mathbf{8}$ using $\mathrm{ADMB}$ chloride, pyridine, and DMAP followed by removing the 3-O-PMB ether via cerium(IV) ammonium nitrate, benzoylation at C-3, and two-step removal of the anomeric allyl group using Felkin's catalyst and $\mathrm{OsO}_{4}$ to give the lactol. The lactol was finally transformed into the trichloroacetimidate donor 4 by reaction with 2,2,2-trichloroacetonitrile under catalysis by $\mathrm{K}_{2} \mathrm{CO}_{3}$. Coupling of 3 with the donor 4 gave exclusively the $\beta$-linked disaccharide 9 due to the presence of the 2-O-ADMB group, which subsequently was removed in high yield using acetyl chloride in methanol to give 10. The protecting group arrangement in $\mathbf{1 0}$ was conducive to facile inversion at C-2 of the nonreducing residue via triflate ester formation followed by sonication-induced displacement with tetra- $n$-butylammonium acetate $^{37}$ to give the manno-gluco disaccharide intermediate 11 in $77 \%$ yield with no detectable gluco-gluco isomer. Pan removal of the ester protecting groups in 11 gave triol 12, which after 2,3-acetonide and $\mathrm{ADMB}$ ester installation gave 14. Replacement of the 2,3-acetonide with acetate esters gave the key 


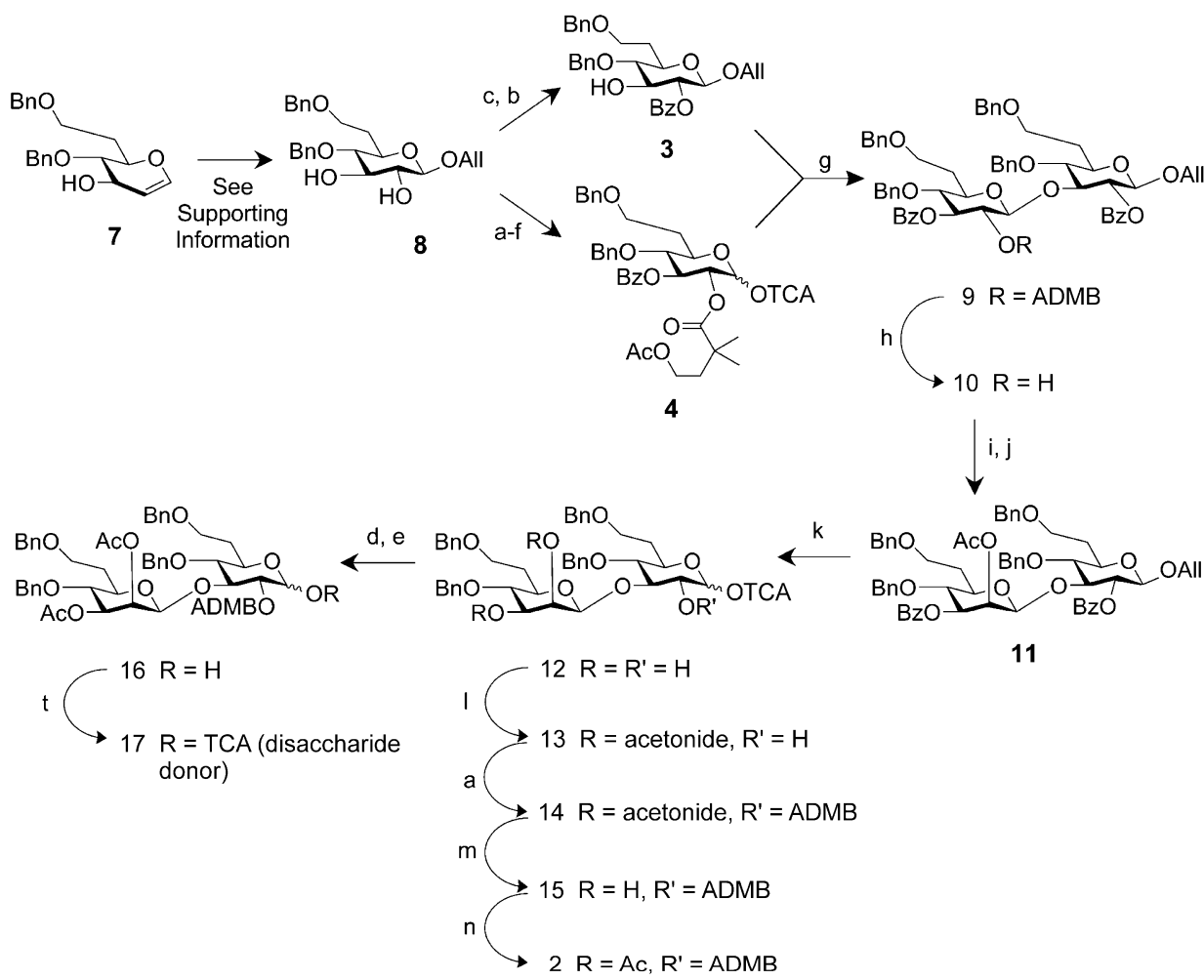

Figure 3. Synthesis of disaccharide donor 17.Chemical manipulations involved in the preparation of the monosaccharide building blocks 3 and $\mathbf{4}$ and their coupling to create precursor compound 9 ready for further elaboration to the disaccharide donor 17. Reagents and conditions: (a) 4-acetoxy2,2-dimethylbutanoyl chloride, pyridine, 4-(dimethylamino)pyridine, $80{ }^{\circ} \mathrm{C}, 12 \mathrm{~h}, 81 \%$; (b) cerium(IV) ammonium nitrate, acetonitrile: $\mathrm{H}_{2} \mathrm{O}(9: 1 \mathrm{v} /$ v), $5{ }^{\circ} \mathrm{C}, 10 \mathrm{~min}$; (c) benzoyl chloride, pyridine, 4-(dimethylamino)pyridine, rt, $12 \mathrm{~h}, 96 \%$, steps p-q overall; (d) Felkin's catalyst, tetrahydrofuran, rt, $30 \mathrm{~min}$; (e) $\mathrm{OsO}_{4}$, 4-methylmorpholine $\mathrm{N}$-oxide, rt, $12 \mathrm{~h}, 91 \%$ steps $\mathrm{r}-\mathrm{s}$ overall; (f) $\mathrm{K}_{2} \mathrm{CO}_{3}$ powder ( $-325 \mathrm{mesh}$ ), trichloroacetonitrile, rt, $12 \mathrm{~h}$; (g) trimethylsilyl trifluoromethanesulfonate 0.1 equiv, $\mathrm{CH}_{2} \mathrm{Cl}_{2}$, rt, $2 \mathrm{~h}, 95 \%$; (h) acetyl chloride, methanol, $\mathrm{CH}_{2} \mathrm{Cl}_{2}, 0{ }^{\circ} \mathrm{C}$ to $\mathrm{rt}, 12 \mathrm{~h}, 89 \%$; (i) pyridine, $\mathrm{CH}_{2} \mathrm{Cl}_{2}$, trifluoromethanesulfonic anhydride, $0{ }^{\circ} \mathrm{C}, 5 \mathrm{~min}$; (j) tetrabutylammonium acetate, toluene, sonication, rt, $30 \mathrm{~min}$, steps $\mathrm{c}-\mathrm{d} 90 \%$ overall; (k) sodium methoxide, methanol, tetrahydrofuran, $\mathrm{rt}, 12 \mathrm{~h}$; (1) p-toluenesulfonic acid, acetone, 2,2-dimethoxypropane, rt, 30 min; (m) acetic acid, $\mathrm{H}_{2} \mathrm{O}(4: 1, \mathrm{v} / \mathrm{v}), 65^{\circ} \mathrm{C}, 1 \mathrm{~h}$; (n) acetic anhydride, pyridine, $\mathrm{CH}_{2} \mathrm{Cl}_{2}$, 4-(dimethylamino)pyridine, rt, $12 \mathrm{~h}, 65 \%$ steps e-i overall. For complete reaction conditions, see Supporting Information. $\mathrm{Bn}=$ Benzyl; $\mathrm{Bz}=$ Benzoyl; All = Allyl; $\mathrm{Ac}=$ acetyl; $\mathrm{TCA}=$ trichloroacetimidate; $\mathrm{ADMB}=4-$ acetoxy-2,2-dimethyl butanoyl.

disaccharide 2, which provided a convenient point for storing material for future assembly operations, and may be elaborated conveniently to either a modular donor or acceptor. In preparation for iterative assembly, two-step cleavage of the allyl glycoside and reaction of the resulting hemiacetal with trichloroacetonitrile gave the key disaccharide donor 17 , also a stable intermediate that could be stored in the freezer for months.

Assembly to Protected Hexasaccharide. Assembly of the hexasaccharide backbone was achieved via three iterative multistep coupling cycles starting with installation of a masked amine linker synthon at the reducing end of the saccharide backbone (Figure 4). Trimethylsilyl trifluoromethanesulfonate (TMSOTf)-mediated coupling of $\mathbf{1 7}$ with the protected linker acceptor $18^{38}$ gave the desired $\beta$-anomer 19 in $87 \%$ yield. Sodium methoxide catalyzed removal of the three ester groups in 19 gave triol 20, the 2,3-cis-diol of which was protected by an acetonide ketal to give alcohol 21 . With the $\mathrm{C}-2$ alcohol group of the gluco-residue now isolated, inversion to the mannoconfiguration was achieved through a two-step process involving oxidation to the ketone using Dess-Martin periodinane ${ }^{39}$ followed by reduction of the crude ketone using $\mathrm{NaBH}_{4}$. The reduction proceeded cleanly in less than $5 \mathrm{~min}$ with 9:1 stereoselectivity in favor of the desired manno-manno configured disaccharide $\mathbf{2 2}$. While $\mathbf{2 2}$ was separable from the manno-gluco disaccharide $\mathbf{2 1}$ at this stage, which presented an opportunity to recycle recovered $\mathbf{2 1}$, it was found that for subsequent larger runs the mixture could be carried through the next two steps without impact on yield or quality of the product. Thus, the 1:9 mixture of 21:22 was benzoylated at the C-2 and after removal of the acetonide gave diol 23 in 55\% overall five-step yield from 20. The structure of 23 was established by a combination of 1-D and 2-D NMR spectroscopy with a particular focus on on two properties: (i) the ${ }^{1} J_{\mathrm{C} 1, \mathrm{H} 1}$ coupling constant, and (ii) the downfield broad singlet signals corresponding to the $\mathrm{C}-2$ ring protons of $\beta$ manno anomeric linkages. These signals would prove diagnostic for determining the stereochemistry of the anomeric linkages during assembly of larger oligosaccharides. In the case of $\mathbf{2 3}$ the ${ }^{1} J_{\mathrm{C} 1, \mathrm{H} 1}$ for the two anomeric carbons were 155.2 and $157.8 \mathrm{~Hz}$, indicative of $\beta$-linked D-pyranoses. ${ }^{40}$ To provide further support of the structural assignment of 23 , a sample of the manno-gluco isomer $\mathbf{2 1}$ was treated with benzoyl chloride then acetic acid to give an authentic sample of diol 24, NMR analysis of which showed the expected downfield triplet $\left(\mathrm{ppm},{ }^{3} \mathrm{~J}=\mathrm{Hz}\right.$ ) for the $\mathrm{C}-2$ ring proton consistent with a $\beta$-gluco configuration. Coupling of disaccharide diol acceptor 23 with disaccharide donor 17 at $-20{ }^{\circ} \mathrm{C}$ resulted in tetrasaccharide alcohol 25 in $86 \%$ yield (Figure 5 ). After benzoylation of the remaining C-2 hydroxyl, the tetrasaccharide 26 was prepared for inversion of 

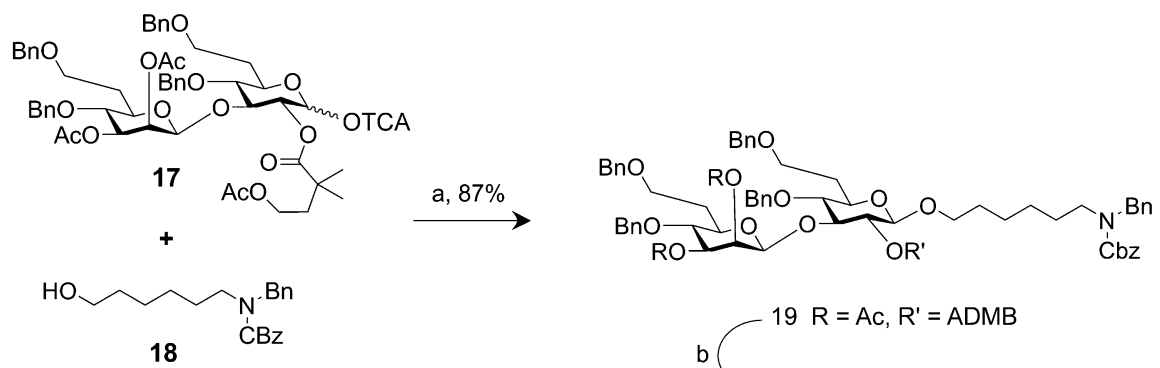

18
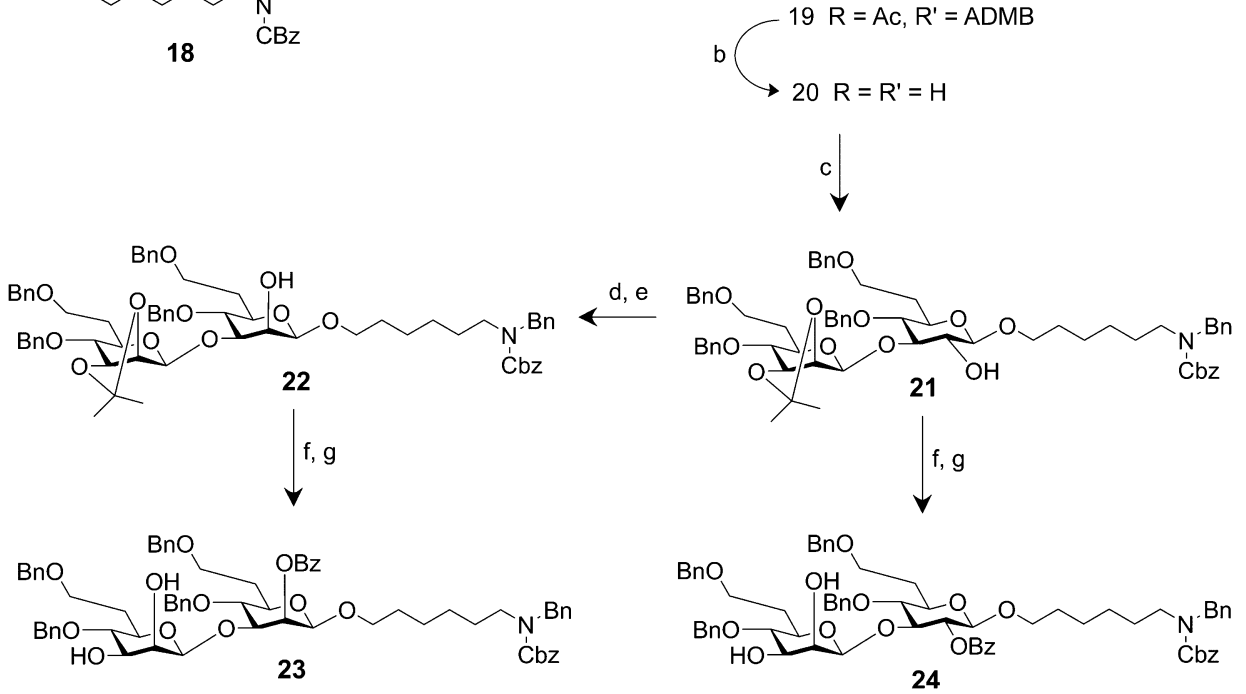

Figure 4. Initial coupling cycle to attach the first disaccharide to the linker. Chemical evolutions in the first of the coupling cycles whereby the disaccharide donor $\mathbf{1 7}$ is attached to the linker synthon to initiate the saccharide backbone. Subsequent elaborations develop this compound to the acceptor diol 23 ready for coupling to further disaccharides to extend the chain. Reagents and conditions: (a) TMSOTf 0.1 equiv, $\mathrm{CH}_{2} \mathrm{Cl}_{2}$, rt, 2 h; (b) sodium methoxide, methanol, tetrahydrofuran, rt; (c) p-toluenesulfonic acid, acetone, 2,2-dimethoxypropane, rt, 2 h; (d) Dess-Martin Reagent, $\mathrm{CH}_{2} \mathrm{Cl}_{2}$ (wet), rt, $24 \mathrm{~h}$; (e) dichloromethane:methanol (1:1), $0{ }^{\circ} \mathrm{C}, \mathrm{NaBH}_{4}, 5$ min; (f) benzoyl chloride, pyridine, $\mathrm{CH}_{2} \mathrm{Cl}_{2}$, 4(dimethylamino)pyridine, rt, $12 \mathrm{~h}$; (g) acetic acid, $\mathrm{H}_{2} \mathrm{O}(4: 1, \mathrm{v} / \mathrm{v}), 50{ }^{\circ} \mathrm{C}, 12 \mathrm{~h}$. For complete reaction conditions see Supporting Information. $\mathrm{Bn}=$ Benzyl; Bz = Benzoyl; Ac = acetyl; TCA = trichloroacetimidate; ADMB = 4-acetoxy-2,2-dimethyl butanoyl; Cbz = benzyloxycarbonyl.

the lone gluco-residue to the desired manno isomer. In contrast to the disaccharide 19 which could accommodate removal of all esters en route to isolating the gluco C-2 hydroxyl, the presence of the benzoyl esters in $\mathbf{2 6}$ precluded the use of standard sodium methoxide de-esterification conditions. However, others have demonstrated selective removal of acetyl esters in the presence of benzoyl esters using magnesium methoxide. ${ }^{41,42}$ Indeed, treatment of $\mathbf{2 6}$ with magnesium methoxide smoothly removed the acetyl esters including the acetyl ester of the $\mathrm{ADMB}$ group, which spontaneously lactonized to give triol 27 in $75 \%$ yield. In analogy with triol 20 , triol 27 was subjected to the same process of acetonide installation, Dess-Martin oxidation, sodium borohydride reduction, benzoylation, and acetonide removal to give diol 30 in $43 \%$ overall five-step yield from triol 27.

For the final iteration, coupling of disaccharide donor 17 with diol acceptor 30 at $-20{ }^{\circ} \mathrm{C}$ gave hexasaccharide 31 in $50 \%$ direct yield along with recovery of $40 \%$ unreacted diol 30, which was easily separated chromatographically and recycled (Figure 5). Following the procedures used at the tetrasaccharide level, hexasaccharide 31 was subjected to the same sevenstep sequence to achieve inversion at C-2 of the lone glucoisomer to afford the hexasaccharide diol 32 in $31 \%$ overall yield from 31. While hexasaccharide 32 could have been extended further to the octasaccharide, and indeed a small amount of a protected octasaccharide was produced, minor amounts of partially debenzoylated byproducts were observed during the sequence from 31 to 32 , indicating the upper limit of the utility of this modular approach was being approached. The last hurdle prior to the deblock sequence was to differentiate the nonreducing end 2,3-cis-diol to allow for future regioselective incorporation of the 2-O-acetyl group. For this, the wellestablished approach of 2,3-ortho-ester formation followed by in situ dilute acid-catalyzed axial-selective ring opening to give the C-2 ester was adapted. ${ }^{43,44}$ Thus, treatment of cis-diol 32 with trimethyl orthobenzoate gave the orthoester which was rearranged selectively to the C-2 ester by addition of water to the reaction mixture. Finally, the sole remaining hydroxyl group at $\mathrm{C}-3$ of the nonreducing end residue was benzylated under acidic conditions using benzyl 2,2,2-trichloroacetimidate ${ }^{45}$ to give hexasaccharide 33 . With hexasaccharide 33 in hand, the complete $\beta$-manno-heptose backbone was in place and all C-2 hydroxyl groups were differentiated and staged for future incorporation of the 2-O-acetyl groups.

Final Elaboration and Deprotection. Final processing and deprotection of $\mathbf{3 3}$ to synthetic antigen $\mathbf{1}$ was accomplished using a simple three-step sequence (Figure 5). The six 2-Obenzoyl esters were removed and replaced with acetyl esters to give hexa-O-acetyl product 34 in $57 \%$ yield. The benzylic protecting groups were removed en masse within $24 \mathrm{~h}$ by hydrogenolysis $\left(2 \mathrm{~atm} \mathrm{H}_{2}\right.$ ) catalyzed by $10 \% \mathrm{Pd}$ on carbon in a solution of THF: $\mathrm{H}_{2} \mathrm{O}(2: 1 \mathrm{v} / \mathrm{v})$ with 1 equiv of $\mathrm{HCl}$ added to suppress $\mathrm{O}$ - to $\mathrm{N}$-acetyl migration to give the desired ${ }_{\mathrm{SH}} \mathrm{CPS} 1$ in $65 \%$ after purification by size exclusion chromatography and lyophilization. No $\mathrm{O}$ - to $\mathrm{N}$-acetyl migration was detected, nor was any 2- to 3-O-acetyl migration detected on the nonreducing end. Matrix-assisted laser desorption/ionization mass spectrometry (MALDI-MS) of ${ }_{\mathrm{SH}} \mathrm{CPS} 1$ (Figure 6, panel A) 


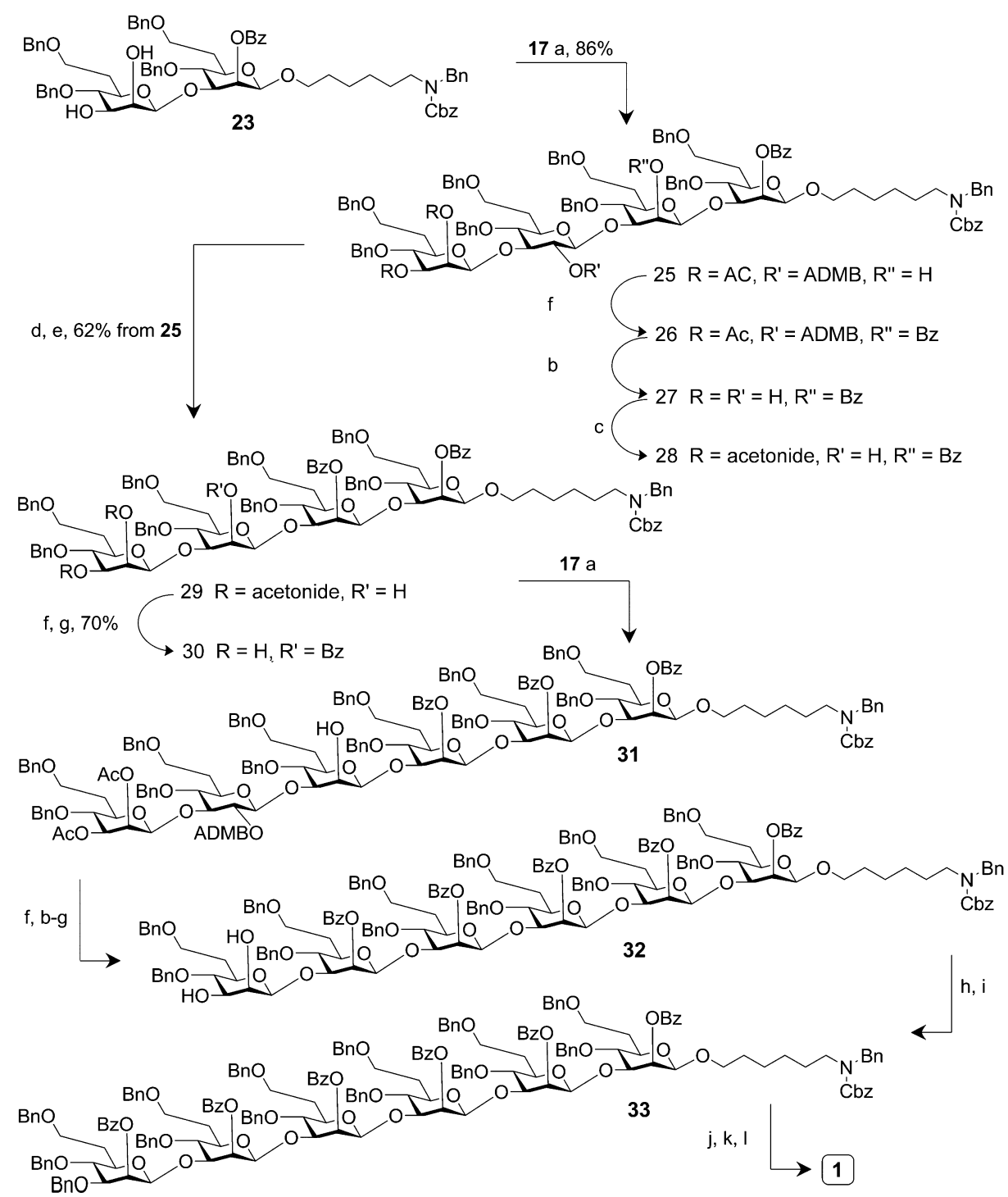

Figure 5. Iterative coupling cycles to assemble the target hexasaccharide 1. Chemical manipulations involved in the second and third coupling cycles installing the disaccharide donor 17 onto the disaccharide diol acceptor 23 and subsequently the tetrasaccharide diol acceptor 30 to generate the fulllength hexasaccharide. Succeeding elaborations replace the six 2-O-benzoyl esters with acetyl esters to give hexa- $\mathrm{O}$-acetyl hexasaccharide ready for final deprotection to give the target antigen 1. Reagents and conditions: (a) TMSOTf 0.1 equiv, $\mathrm{CH}_{2} \mathrm{Cl}_{2}$, rt, $2 \mathrm{~h}$; (b) magnesium methoxide, methanol, tetrahydrofuran, rt; (c) p-toluenesulfonic acid, acetone, 2,2-dimethoxypropane, rt, 2 h; (d) Dess-Martin Reagent, $\mathrm{CH}_{2} \mathrm{Cl}_{2}$ (wet), rt, 24 h; (e) dichloromethane:methanol $(1: 1), 0{ }^{\circ} \mathrm{C}, \mathrm{NaBH}_{4}, 5 \mathrm{~min}$; (f) benzoyl chloride, pyridine, $\mathrm{CH}_{2} \mathrm{Cl}_{2}, 4$-(dimethylamino)pyridine, rt, $12 \mathrm{~h}$; $(\mathrm{g})$ acetic acid, $\mathrm{H}_{2} \mathrm{O}(4: 1, \mathrm{v} / \mathrm{v}), 50^{\circ} \mathrm{C}, 12 \mathrm{~h}$; (h) trimethylorthobenzoate, $\mathrm{CH}_{2} \mathrm{Cl}_{2}, \mathrm{CH}_{3} \mathrm{CN}$, cat. camphorsulfonic acid, rt, $1 \mathrm{~h}$, then $\mathrm{H}_{2} \mathrm{O}, 5 \mathrm{~h}$; (i) ytterbium(III) trifluoromethanesulfonate, $p$-methoxybenzyl trichloroacetimidate, toluene, rt, $3 \mathrm{~h}$; $(\mathrm{j}) \mathrm{NaOMe}$, methanol, tetrahydrofuran, rt, $12 \mathrm{~h}$; $(\mathrm{k})$ acetic anhydride, pyridine, $\mathrm{CH}_{2} \mathrm{Cl}_{2}$, 4-(dimethylamino)pyridine, rt, 12 h, $57 \%$ over two steps; (l) $10 \% \mathrm{Pd} / \mathrm{C}$, methanol, $\mathrm{H}_{2} \mathrm{O}, \mathrm{HCl}(1 \mathrm{equiv}), \mathrm{H}_{2}(2$ atm.), rt, 43 h, 67\%. For complete reaction conditions, see Supporting Information. Bn = Benzyl; Bz = Benzoyl; Ac = acetyl; ADMB = 4-acetoxy-2,2dimethyl butanoyl; $\mathrm{Cbz}=$ benzyloxycarbonyl.

identified major peaks at $m / z=1427$ and $m / z=1449$ (calculated values: $\mathrm{C}_{60} \mathrm{H}_{99} \mathrm{NO}_{37} \mathrm{~m} / z=1426.6 ; \mathrm{C}_{60} \mathrm{H}_{99} \mathrm{NO}_{37} \mathrm{Na}$ $m / z=1448.6)$. The ${ }^{13} \mathrm{C}$ NMR and ${ }^{1} \mathrm{H}$ NMR spectra of the synthetic antigen 1 (Figure 6, panels $\mathrm{B}$ and $\mathrm{C}$ ) were consistent with this molecule being $1 \rightarrow 3$ linked 2 - $O$-acetyl-6-deoxy- $\beta$-Dmanno-heptopyranose, which gave confidence to proceed with conjugation and immunogenicity studies.

Conjugation to Carrier Protein. Although ${ }_{\mathrm{SH}} \mathrm{CPS} 1$ was likely to be of sufficient size to act as an epitope to generate specific antibodies, it was considered to be unlikely to be sufficiently immunogenic on its own to stimulate antibodies during immunization. Polysaccharides such as the mannoheptopyranose CPS are generally T-independent type 2 antigens relying on cross-linking of surface immunoglobulin molecules present on antigen-specific B cells to stimulate antibody responses. ${ }^{46-48}$ With a molecular weight of $1524 \mathrm{Da}$, ${ }_{\mathrm{SH}} \mathrm{CPS} \mathbf{1}$ is not large enough to act in this manner, and further its small size makes rapid clearance from the body before engaging with the immune system a real possibility. For larger polysaccharides, conjugation to carrier proteins is the traditional method to allow polysaccharides to act as T-dependent antigens with the concomitant boost in antibody responses, promotion of class switching and increased B-cell memory formation. ${ }^{49}$ Additional benefits of this strategy for oligosaccharides such as synthetic hexasaccharide $\mathbf{1}$ are that clustering of multiple oligosaccharides on a single protein may act to 

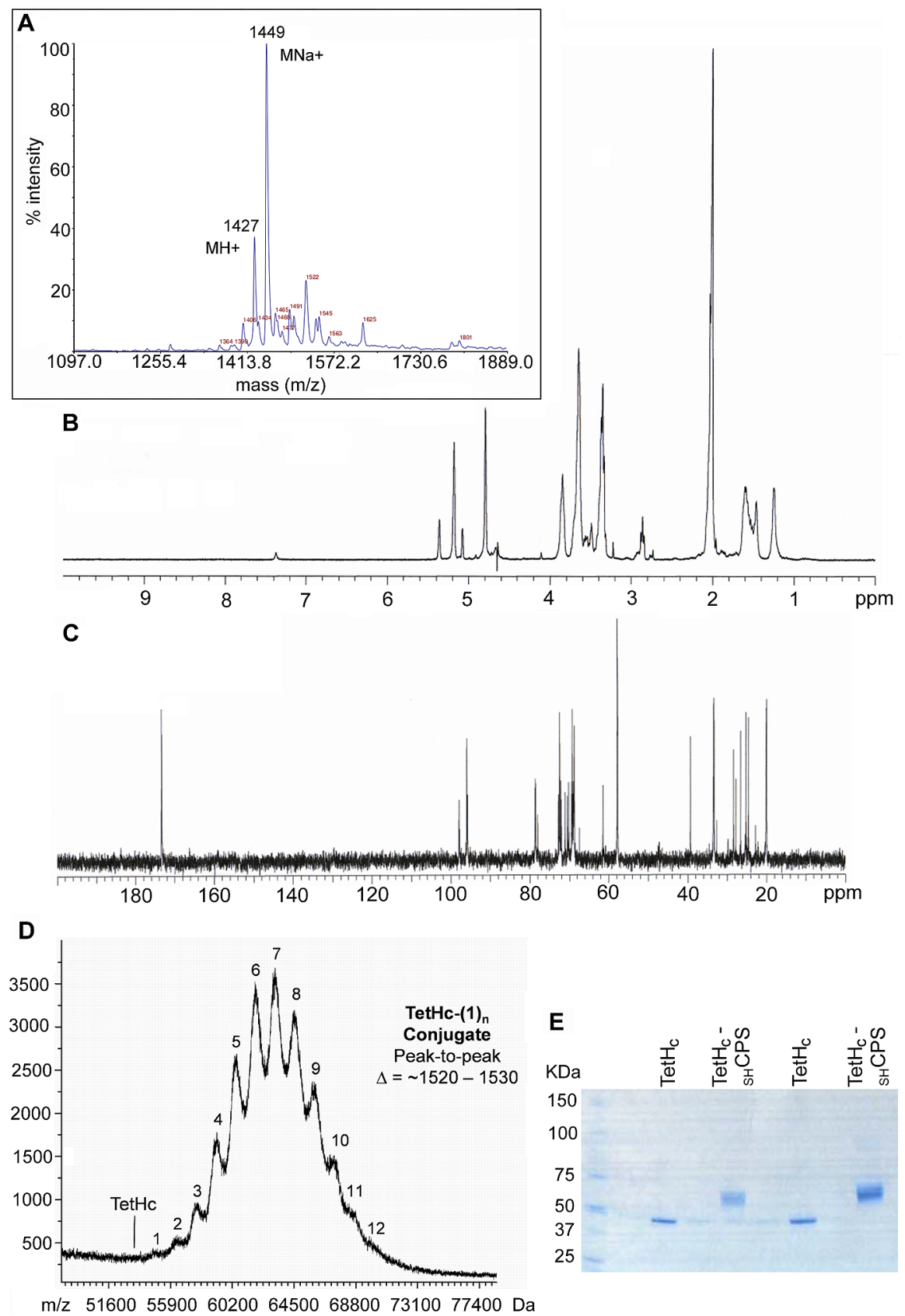

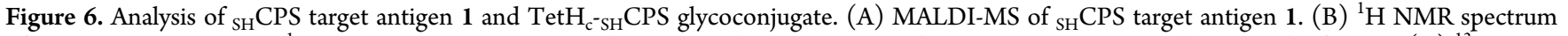
of ${ }_{\mathrm{SH}} \mathrm{CPS}$ target antigen 1. ${ }^{1} \mathrm{H}$ NMR spectra were acquired in $\mathrm{D}_{2} \mathrm{O}$ with the $\mathrm{HOD}$ signal at $4.75 \mathrm{ppm}$ serving as the internal reference. (C) ${ }^{13} \mathrm{C}$ NMR spectrum of ${ }_{S H} \mathrm{CPS}$ target antigen 1 with 1,4-dioxane (67.19 ppm) served as the internal standard. (D) MALDI-MS revealing 12 discrete peaks reflecting the incorporation of between 1 and $12{ }_{S H} \mathrm{CPS}$ hexasaccharides per $\mathrm{TetH}_{\mathrm{c}}$ protein as indicated above each peak. Unconjugated TetHc would be present as a peak at approximately $\mathrm{m} / z 53000$ as indicated. The increments match the expected mass of the hexasaccharide and linker following incorporation using the selected chemistry (1524 Da per hexasaccharide incorporated). (E) SDS-PAGE with subsequent Coomassie staining demonstrates the increased molecular weight of the $\mathrm{TetH}_{\mathrm{c}}-\mathrm{SHCPS}$ glycoconjugate compared to unconjugated $\mathrm{TetH}_{\mathrm{c}}$ protein. $\mathrm{No}$ unconjugated TetHc was visible in the glycoconjugate. Loading was with $3.2 \mu \mathrm{g}$ of $\mathrm{TetH}_{\mathrm{c}}$ per lane and $3.4 \mu \mathrm{g}$ and $6.8 \mu \mathrm{g}$ of conjugate in the left and right lanes respectively.

simulate a larger polysaccharide, and that the resulting glycoconjugate may be retained for longer in the body giving more time to engage with and stimulate the immune system. As such, ${ }_{\mathrm{SH}} \mathrm{CPS}$ was designed to incorporate an amine-terminated alkyl linker to allow conjugation to a carrier protein. The recombinant carrier protein was the nontoxic Hc domain of tetanus toxin $\left(\mathrm{TetH}_{\mathrm{c}}\right)$, primarily chosen due to the presence of known T-cell epitopes and because tetanus toxoid is used as the carrier in a number of licensed glycoconjugate vaccines. ${ }^{50}$
Conjugation was effected by linking hexasaccharide 1 to $\mathrm{TetH}_{\mathrm{c}}$ using a glutaric acid linker as described by Bromuro et al. ${ }^{51}$ The glycoconjugate was purified by size exclusion centrifugation and lyophilized. The resulting glycoconjugate $\left(\mathrm{TetH}_{\mathrm{c}^{-} \mathrm{SH}} \mathrm{CPS}\right)$ was present as a slightly diffuse band with reduced mobility by SDSPAGE compared to unconjugated $\mathrm{TetH}_{\mathcal{c}}$, indicating the incorporation of glycan. The MALDI-MS data for the conjugate clearly show successive signals at $\Delta=1524 \mathrm{amu}$, attributable to increasing valency of the fully intact hexasaccharide plus the 
glutarate linker. While $2-O$ to $3-O-A c$ migration at the nonreducing terminal residue cannot be unequivocally ruled out, all of the Ac esters in the hexasaccharide antigen are present (Figure 6, panels $\mathrm{D}$ and $\mathrm{E}$ ). It was possible to see 12 discrete peaks arranged in a generally normal distribution with a mean of approximately 6.5 hexamers per $\mathrm{TetH}_{\mathrm{c}}$ protein $(15 \%$ glycan by weight), which was consistent with the degree of reduced mobility by SDS-PAGE. No unconjugated $\mathrm{TetH}_{\mathrm{c}}$ was visible by mass spectrometry or by SDS-PAGE.

Conjugate Immunogenicity. To assess whether the synthetic hexasaccharide was capable of raising relevant immune responses, groups of five $\mathrm{BALB} / \mathrm{c}$ mice were immunized using a prime-boost-boost strategy with the $\mathrm{TetH}_{\mathrm{c}^{-} \mathrm{SH}} \mathrm{CPS}$ glycoconjugate or a mix of unconjugated ${ }_{\mathrm{SH}} \mathrm{CPS}$ and $\mathrm{TetH}_{\mathrm{c}}$. Following the final boost, sera was recovered from tail veins and titers of IgG and IgM recognizing purified native CPS were determined by ELISA (Table 1). Mice

Table 1. Antibody Titers versus Native CPS Following Immunization with $\mathrm{TetH}_{\mathrm{c}^{-} \mathrm{SH}} \mathrm{CPS}$ Glycoconjugate

\begin{tabular}{|c|c|c|c|}
\hline \multirow[b]{2}{*}{ vaccine received } & \multicolumn{2}{|c|}{$\begin{array}{l}\text { antibody reciprocal } \\
\text { end point titer }\end{array}$} & \multirow[b]{2}{*}{ IgG:IgM ratio } \\
\hline & $\operatorname{IgM}$ & $\operatorname{IgG}$ & \\
\hline \multirow[t]{5}{*}{ TetH $_{c}-{ }_{\text {sH }}$ CPS conjugate ${ }^{b}$} & 25 & 200 & 8 \\
\hline & 50 & 100 & 2 \\
\hline & 50 & 25 & 0.5 \\
\hline & 200 & 400 & 2 \\
\hline & 25 & 25 & 1 \\
\hline \multirow[t]{5}{*}{$\mathrm{TetH}_{\mathrm{c}} / \mathrm{sH}_{\mathrm{CPS}} \mathrm{mix}^{b}$} & $<25$ & $<25$ & $\mathrm{~N} / \mathrm{A}$ \\
\hline & $<25$ & $<25$ & $\mathrm{~N} / \mathrm{A}$ \\
\hline & $<25$ & $<25$ & N/A \\
\hline & $<25$ & $<25$ & $\mathrm{~N} / \mathrm{A}$ \\
\hline & $<25$ & $<25$ & N/A \\
\hline
\end{tabular}

${ }^{a}$ The limit of detection for this assay was a reciprocal end point of 25 . ${ }^{b}$ Each row represents the result from an individual mouse.

receiving the mix of ${ }_{\mathrm{SH}} \mathrm{CPS}$ and $\mathrm{TetH}_{\mathrm{c}}$ had a CPS-specific antibody titer which was below the limit of detection in this assay. In contrast, all of the mice receiving the $\mathrm{TetH}_{\mathrm{c}}{ }^{-} \mathrm{SH}$ CPS glycoconjugate had detectable levels of $\operatorname{IgG}$ and $\operatorname{IgM}$ recognizing native CPS, demonstrating that the synthetic approach utilized here successfully generated immunologically relevant glycoconjugates and also the necessity for conjugation to a carrier protein for the development of detectable immune responses. There was a bias toward IgG in the responses of four of the five mice immunized with $\mathrm{TetH}_{\mathrm{c}^{-} \mathrm{SH}} \mathrm{CPS}$, as is consistent with responses observed for other glycoconjugate vaccines where there is expected to be a switch from IgM to IgG production. Interestingly, the titer of the CPS-specific IgG response to this glycoconjugate (reciprocal end point titer of $25-400)$ is several orders of magnitude lower than what has previously been observed for responses generated against native CPS conjugates (reciprocal end point titer of $\sim 100000^{17,18}$ ). The reason for this disparity is unclear at present, although one hypothesis currently being evaluated involves the relative abundance within the native and synthetic CPS molecules of the repeating internal epitope (present in great excess in native CPS) and the terminal epitope at the nonreducing end of the glycan (present in relatively greater abundance in synthetic CPS).. It is possible that antibodies raised to different parts of the CPS molecule play different roles in protection of the host, for example, opsonizing antibodies may only be generated in response to certain epitopes.

Protective Efficacy. Murine models of melioidosis using $\mathrm{BALB} / \mathrm{c}$ mice and the intraperitoneal route of infection are well established and have been used extensively to evaluate vaccine candidates (for reviews, see refs $8-10,52,53$ ). The protective efficacy of the $\mathrm{TetH}_{\mathrm{c}^{-} \mathrm{SH}} \mathrm{CPS}$ glycoconjugate was assessed in two independent challenge studies (see Experimental Procedures section for details of the schedules), starting with a preliminary study to establish approximate $p$ values and effect size to inform power calculations for confirmatory studies (groups received; (i) $\mathrm{TetH}_{\mathrm{c}-\mathrm{sH}} \mathrm{CPS}$ glycoconjugate and (ii) adjuvant only; challenge was $1.02 \times 10^{5}$ colony forming units (CFU) of $B$. pseudomallei $\mathrm{K} 96243$ (approximately $137 \times \mathrm{LD}_{50}$ ); $n=6$ per group). The results from the preliminary study were such that a similarly sized study was sufficient to verify the findings. Additional groups were included in this study to further examine the protection observed (groups received; (i) $\mathrm{TetH}_{\mathrm{c}^{-} \mathrm{SH}} \mathrm{CPS}$ glycoconjugate; (ii) adjuvant only; (iii) a mix of unconjugated ${ }_{\mathrm{SH}} \mathrm{CPS}$ and $\mathrm{TetH}_{\mathrm{c}}$ protein; and (iv) ${ }_{\mathrm{SH}} \mathrm{CPS}$ only; challenge was with $8.9 \times 10^{4} \mathrm{CFU}$ of $\mathrm{B}$. pseudomallei K996243 (approximately $120 \times \mathrm{LD}_{50}$ ); $n=6$ per group). The survival curves of the groups receiving adjuvant only or the $\mathrm{TetH}_{\mathrm{c}}{ }^{-\mathrm{SH}} \mathrm{CPS}$ glycoconjugate were examined to assess consistency between the two studies and were not significantly different ( $p=0.1380$ and $p=0.3112$, respectively). Therefore, further analysis was conducted using pooled data sets (Figure 7).

As expected and in line with the high challenge doses used in these studies $\left(\geq 120 \times \mathrm{LD}_{50}\right)$, all control mice immunized with adjuvant succumbed rapidly to disease, with 11 of 12 mice succumbing within 3 days. In contrast, only 4 of the 12 mice immunized with $\mathrm{TetH}_{\mathrm{c}^{-} \mathrm{SH}} \mathrm{CPS}$ had succumbed to disease by the end of the study at day 35 . Of the surviving eight mice, no bacteria were detectable in the lungs, liver, and spleen of three, suggesting, at least within the confines of the organs tested and the limit of detection of the assay, that these mice had cleared infection. The remaining five mice had bacteria detectable in the liver and spleen ( 2 of 5 mice) or in lungs, liver, and spleen ( 3 of 5 mice). The highest numbers of bacteria were present in the spleen (median $2.7 \times 10^{6} \mathrm{CFU}$, range $2.0 \times 10^{4} \mathrm{CFU}$ to 3.2 $\times 10^{7} \mathrm{CFU}$ ) with lower levels in the lungs (median $2.3 \times 10^{2}$ $\mathrm{CFU}$, range $8.0 \times 10^{0} \mathrm{CFU}$ to $2.5 \times 10^{3} \mathrm{CFU}$ ) and liver (median $3.3 \times 10^{3} \mathrm{CFU}$, range $4.0 \times 10^{1} \mathrm{CFU}$ to $6.6 \times 10^{4}$ $\mathrm{CFU})$ suggesting an ongoing infection with the mice likely to succumb to infection without further medical intervention. Such a high level of survival, and indeed the presence of apparent bacterial clearance in a subset of mice, was unexpected given the very low level of antigen-specific antibodies detectable after immunization. Previous studies have undoubtedly indicated the need for humoral immunity in vaccine-induced protection (for reviews, see refs 8-10), and although there have only been limited studies where antibody titers have been directly linked to outcome on an individual animal basis, ${ }^{54}$ it is clear from other studies using conjugated and unconjugated native capsular polysaccharide that groups with higher antigenspecific antibody titers fare better than groups with lower titers. Previous work has identified differences between the immunogenicity of terminal and internal polysaccharide epitopes in model antigens ${ }^{55}$ and some evidence exists with Francisella tularensis that the avidity of antibodies targeting terminal epitopes can be higher than for antibodies targeting internal epitopes. ${ }^{56}$ It may be that, although stimulating a 
A

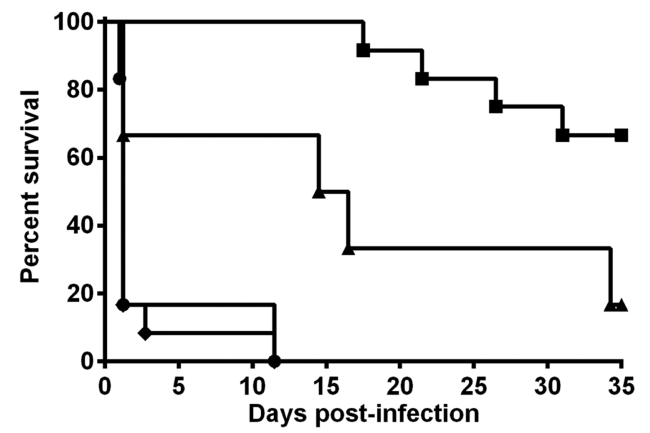

B

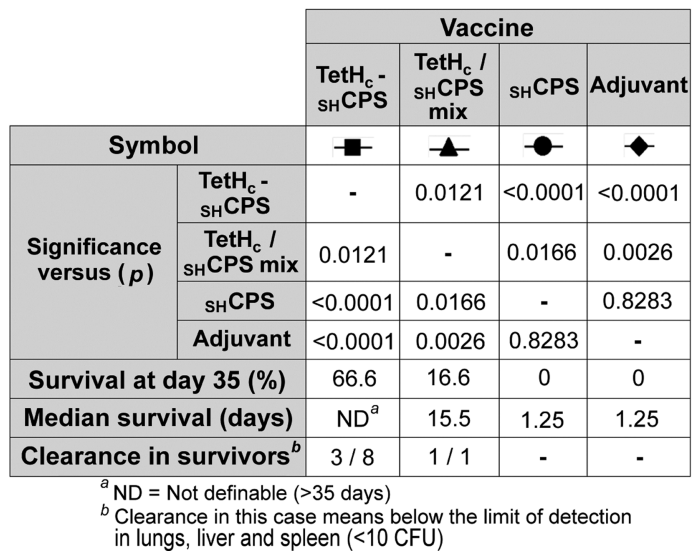

Figure 7. Protective efficacy of TetHc-SHCPS glycoconjugate. (A) Kaplan-Meier plot displaying survival of immunized BALB/c mice over 35 days following intraperitoneal infection with 120 to $137 \times$ $\mathrm{LD}_{50}$ of B. pseudomallei strain K96243. (B) Data table detailing significance after analyzing the survival data using a Log-Rank (MantelCox) test. The $\mathrm{TetH}_{\mathrm{c}-\mathrm{sH}} \mathrm{CPS}$ glycoconjugate offers significantly better protection than all the other vaccines tested. Median survival time and clearance in surviving mice is indicated.

relatively low titer of antibody, the small size and different spectrum of epitopes within ${ }_{\mathrm{SH}} \mathrm{CPS}$ promotes development of highly functional antibodies responsible for the high levels of protection observed. This possibility, and methods to exploit it for improved vaccines, is currently under study.

In summary, this is the first demonstration of the chemical synthesis of an immunologically relevant and protective hexasaccharide fragment of the capsular polysaccharide of $B$. pseudomallei and serves as the rational starting point for the development of an effective licensed vaccine for this emerging infectious disease. The synthetic B. pseudomallei CPS hexamer material lacks impurities such as endotoxin, and is generated with limited batch-to-batch variation and high quality control standards which are intrinsic to process manufacturing. In addition, the ability to install a functional amine for directed conjugation, and the lack of requirement for containment facilities renders this approach to accessing CPS antigen as a suitable starting point for industrial process development toward licensure. Further, the modular disaccharide strategy described herein is broadly applicable for synthesizing other glycans containing C-6 homologated monosaccharide units in general, and for those connected by 1,2- $\beta$-manno-configured glycosides in particular.

\section{EXPERIMENTAL PROCEDURES}

Chemical Synthesis. Detailed synthetic procedures and characterization data are available online; see Supporting Information.

Glycoconjugate Generation and Analysis. Recombinant tetanus toxin $\mathrm{H}_{\mathrm{c}}$ fragment $\left(\mathrm{Tet}_{\mathrm{c}}\right.$; incorporating amino acids 865-1315 from TetX (NP_783831) of Clostridium tetani E88) was purified from E. coli BL21 $\left(\mathrm{pKS} 1-\mathrm{TetH}_{\mathrm{c}}\right)$ using the method of Sinha et al. ${ }^{57}$ with modifications as previously described. ${ }^{58}$ The $\mathrm{TetH}_{\mathrm{c}-\mathrm{sH}} \mathrm{CPS}$ glycoconjugate was manufactured by linking ${ }_{\mathrm{SH}} \mathrm{CPS}$ to $\mathrm{TetH}_{\mathrm{c}}$ protein using the method of Bromuro et al. ${ }^{5 \mathrm{P}}$ Briefly, hexasaccharide antigen (1) $(3.0 \mathrm{mg}, 4.3 \mu \mathrm{mol})$ was dissolved in $\mathrm{H}_{2} \mathrm{O}(100 \mu \mathrm{L})$ and DMSO $(900 \mu \mathrm{L})$ was added followed by triethylamine $(5 \mu \mathrm{L})$. Solid disuccinyl glutarate (DSG) was added and the suspension was vortexed until a clear solution resulted $(10 \mathrm{~s})$. The solution was incubated at room temperature for $2 \mathrm{~h}$ then the reaction solution was applied directly to the top of a Sephadex G-10 column $(2.5 \mathrm{~cm}$ diameter $\times 14 \mathrm{~cm}$ height) that had been pre-equilibrated with $\mathrm{pH} 4$ water. The column was eluted by gravity with $\mathrm{pH} 4$ water. $4 \mathrm{~mL}$ fractions were collected and analyzed by TLC for carbohydrate content (anisaldehyde staining). Carbohydratecontaining fractions were combined and concentrated to dryness, then reconstituted in $10 \mathrm{mM}$ phosphate-buffered saline (PBS, $\mathrm{pH} 7.0,1000 \mu \mathrm{L}$ ). This solution was added to a solution of $\mathrm{TetH}_{\mathrm{c}}$ protein $(3.08 \mathrm{mg})$ in $10 \mathrm{mM}$ PBS $(1000 \mu \mathrm{L})$ and the reaction solution was incubated for $9.5 \mathrm{~h}$ at $4{ }^{\circ} \mathrm{C}$. The conjugate was purified by repeated centrifugation through a 10 $\mathrm{kDa}$ MWCO Amicon filter until no carbohydrate (free antigen) could be detected in the filtrate $(6 \times 3 \mathrm{~mL}, 10 \mathrm{mM} \mathrm{PBS}, \mathrm{pH}$ 7.0). The concentrate containing the conjugate was lyophilized and reconstituted in water then sampled for analysis by SDSPAGE and MALDI-MS. Absolute protein content was determined using a modified Bradford assay (Bio-Rad) using unconjugated TetHc as a reference standard.

Ethics Statement. Investigations involving animals were carried out according to the requirements of the UK Animal (Scientific Procedures) Act 1986 under project licenses PPL 30/2623 and PPL 30/3026. These project licenses were approved following an ethical review by Dstl's Animal Welfare and Ethical Review Body.

Animal Immunization and Infection. Please see Supporting Information for detailed information on animal care and housing. Studies were performed using female BALB/ cAnNCrl mice (BALB/c; Charles River UK). Mice were immunized via the intraperitoneal route on days 0,14 , and 28 with the various antigens. The mice received $66 \mu \mathrm{g}$ of $\mathrm{TetH}_{\mathrm{c}-\mathrm{SH}} \mathrm{CPS}$ glycoconjugate per dose (containing $10 \mu \mathrm{g}$ of ${ }_{\mathrm{SH}} \mathrm{CPS}$ and $56 \mu \mathrm{g}$ of $\mathrm{TetH}_{\mathrm{c}}$ ) or matching amounts of unconjugated antigen as appropriate. All antigens were formulated in adjuvant containing monophosphoryl lipid A from Salmonella minnesota (25 $\mu \mathrm{g}$ per mouse per dose) and synthetic trehalose dicorynomycolate $(25 \mu \mathrm{g}$ per mouse per dose) as an oil-in-water emulsion of $2 \%$ squalene and $0.2 \%$ Tween 80 (Sigma Adjuvant System, Sigma-Aldrich). Antigen and adjuvant were combined and vortexed thoroughly to mix immediately before administration to mice. Challenges with $B$. pseudomallei K96243 were delivered at day 63 via the intraperitoneal route. The B. pseudomallei $\mathrm{K} 96243$ used in this study was a low passage descendant of the original stock from which genomic DNA was prepared and sequenced by Holden et al. ${ }^{99}$ Prior to use in this study, this stock of strain 
K96243 was verified as being sequence type 10 using the multilocus sequence typing scheme of Godoy et al. ${ }^{.0}$ To prepare challenge material, B. pseudomallei K96243 was inoculated from a glycerol stock into $100 \mathrm{~mL}$ L-broth and incubated for $24 \mathrm{~h}$ at $37{ }^{\circ} \mathrm{C}$ with shaking $(180 \mathrm{rpm})$. The $\mathrm{OD}_{590}$ was adjusted to 0.4 (corresponding to approximately $4 \times$ $10^{8} \mathrm{CFU} / \mathrm{mL}$ ) and diluted in L-broth to the desired concentration for challenge. For organ bacterial enumeration at the end of study, animals were culled and organs removed. These were mashed through $40 \mu \mathrm{m}$ sieves into PBS, serially diluted, and plated onto L-agar.

Analysis of Antibody Responses. Approximately $0.1 \mathrm{~mL}$ of blood was collected from the tail veins of mice 14 days after the final immunizations were performed and serum was removed and stored at $-20{ }^{\circ} \mathrm{C}$ until required. Responses directed against native CPS antigen were assessed by ELISA essentially as previously described ${ }^{17}$ using native CPS purified from B. thailandensis E555:: wbiI (pKnock-Km) ${ }^{61}$ to coat the ELISA plates. A reading of twice background or above was considered positive and the titer was determined to be the reciprocal of the final positive dilution.

Data Analysis. All graphs were produced and analysis conducted using the program GraphPad PRISM v 6.0. Survival data was analyzed using a log rank (Mantel-Cox) test. Significance was assessed at the 95\% confidence level. ChemBioDraw Ultra v 13.0 was used for drawing compounds and reaction schemes. GNU Image Manipulation Program (GIMP) v 2.8 was used to assemble figures into their final format.

\section{ASSOCIATED CONTENT}

\section{S Supporting Information}

The Supporting Information is available free of charge on the ACS Publications website at DOI: 10.1021/acs.bioconjchem.5b00525.

Detailed synthetic procedures; NMR of key intermediates; animal care (PDF)

\section{AUTHOR INFORMATION}

\section{Corresponding Author}

*E-mail: aescott2@dstl.gov.uk. Tel: +44 1980613800.

\section{Author Contributions}

\#Andrew E. Scott and William J. Christ contributed equally to this work.

\section{Author Contributions}

$\triangle_{\text {A. Stewart Campbell and Joann L. Prior also contributed }}$ equally to this work.

\section{Notes}

The authors declare the following competing financial interest(s): At the time of this work, William J. Christ, Gregory J. S. Lohman, Yuhong Guo, Matthew Jones, and A. Stewart Campbell were employees of Ancora Pharmaceuticals Inc which has subsequently been acquired by Corden Pharma International Inc.

\section{ACKNOWLEDGMENTS}

We gratefully acknowledge Tom Laws for his advice on data analysis and statistics and the various animal technicians who supported this work. This work was funded by the United Kingdom Ministry of Defence. The mass spectral data described here were acquired on an Orbitrap Fusion mass spectrometer funded by National Institutes of Health grant 1S10OD010645-01A1.

\section{ABBREVIATIONS}

Ac, acetyl; ADMB, 4-acetoxy-2,2-dimethyl butanoyl; All, allyl; $\mathrm{Bn}$, benzyl; Bz, benzoyl; Cbz, benzyloxycarbonyl; CFU, colony forming units; CPS, capsular polysaccharide; ELISA, enzymelinked immunosorbent assay; MALDI-MS, matrix assisted laser desorption/ionization mass spectrometry; ${ }_{\mathrm{SH}} \mathrm{CPS}$, synthetic hexameric capsular polysaccharide; TCA, trichloroacetimidate; $\mathrm{TetH}_{\mathcal{c}}$ nontoxic $\mathrm{H}_{\mathrm{c}}$ fragment of tetanus toxin; $\mathrm{TetH}_{\mathrm{c}}-{ }_{\mathrm{SH}} \mathrm{CPS}$, glycoconjugate composed of $\mathrm{TetH}_{\mathrm{c}}$ protein covalently linked to ${ }_{\mathrm{SH}} \mathrm{CPS}$; TMSOTf, trimethylsilyl trifluoromethanesulfonate

\section{REFERENCES}

(1) Wiersinga, W. J., Currie, B. J., and Peacock, S. J. (2012) Melioidosis. N. Engl. J. Med. 367, 1035-1044.

(2) Limmathurotsakul, D., Dance, D. A. B., Wuthiekanun, V., Kaestli, M., Mayo, M., Warner, J., Wagner, D. M., Tuanyok, A., Wertheim, H., Yoke Cheng, T., et al. (2013) Systematic Review and Consensus Guidelines for Environmental Sampling of Burkholderia pseudomallei. PLoS Neglected Trop. Dis. 7, e2105.

(3) Meumann, E. M., Cheng, A. C., Ward, L., and Currie, B. J. (2012) Clinical Features and Epidemiology of Melioidosis Pneumonia: Results From a 21-Year Study and Review of the Literature. Clin. Infect. Dis. 54, 362-369.

(4) Currie, B. J., Ward, L., and Cheng, A. C. (2010) The Epidemiology and Clinical Spectrum of Melioidosis: 540 Cases from the 20 Year Darwin Prospective Study. PLoS Neglected Trop. Dis. 4, e 900 .

(5) Dance, D. (2014) Treatment and prophylaxis of melioidosis. Int. J. Antimicrob. Agents 43, 310.

(6) Currie, B. J., Fisher, D. A., Howard, D. M., Burrow, J. N. C., Lo, D., Selva-nayagam, S., Anstey, N. M., Huffam, S. E., Snelling, P. L., Marks, P. J., et al. (2000) Endemic Melioidosis in Tropical Northern Australia: A 10-Year Prospective Study and Review of the Literature. Clin. Infect. Dis. 31, 981-986.

(7) Limmathurotsakul, D., Wongratanacheewin, S., Teerawattanasook, N., Wongsuvan, G., Chaisuksant, S., Chetchotisakd, P., Chaowagul, W., Day, N. P. J., and Peacock, S. J. (2010) Increasing Incidence of Human Melioidosis in Northeast Thailand. Am. J. Trop. Med. Hyg. 82, 1113-1117.

(8) Patel, N., Conejero, L., De Reynal, M., Easton, A., Bancroft, G. J., and Titball, R. W. (2011) Development of vaccines against Burkholderia pseudomallei. Front. Microbiol. 2, 198 DOI: 10.3389/ fmicb.2011.00198.

(9) Choh, L.-C., Ong, G.-H., Vellasamy, K. M., Kalaiselvam, K., Kang, W.-T., Al-Maleki, A. R., Mariappan, V., and Vadivelu, J. (2013) Burkholderia vaccines: are we moving forward? Front. Cell. Infect. Microbiol. 3, 10.3389/fcimb.2013.00005

(10) Silva, E. B., and Dow, S. W. (2013) Development of Burkholderia mallei and pseudomallei vaccines. Front. Cell. Infect. Microbiol. 3,10.3389/fcimb.2013.00010

(11) Knirel, Y. A., Paramonov, N. A., Shashkov, A. S., Kochetkov, N. K., Yarullin, R. G., Farber, S. M., and Efremenko, V. I. (1992) Structure of the polysaccharide chains of Pseudomonas pseudomallei lipopolysaccharides. Carbohydr. Res. 233, 185-193.

(12) Perry, M. B., MacLean, L. L., Schollaardt, T., Bryan, L. E., and Ho, M. (1995) Structural characterization of the lipopolysaccharide O antigens of Burkholderia pseudomallei. Infect. Immun. 63, 3348-52.

(13) Reckseidler, S. L., DeShazer, D., Sokol, P. A., and Woods, D. E. (2001) Detection of Bacterial Virulence Genes by Subtractive Hybridization: Identification of Capsular Polysaccharide of Burkholderia pseudomallei as a Major Virulence Determinant. Infect. Immun. 69, 34-44.

(14) Atkins, T., Prior, R., Mack, K., Russell, P., Nelson, M., Prior, J., Ellis, J., Oyston, P., Dougan, G., and Titball, R. (2002) Character- 
isation of an acapsular mutant of Burkholderia pseudomallei identified by signature tagged mutagenesis. J. Med. Microbiol. 51, 539-553.

(15) DeShazer, D., Waag, D. M., Fritz, D. L., and Woods, D. E. (2001) Identification of a Burkholderia mallei polysaccharide gene cluster by subtractive hybridization and demonstration that the encoded capsule is an essential virulence determinant. Microb. Pathog. 30, 253-269.

(16) Nelson, M., Prior, J. L., Lever, M. S., Jones, H. E., Atkins, T. P., and Titball, R. W. (2004) Evaluation of lipopolysaccharide and capsular polysaccharide as subunit vaccines against experimental melioidosis. J. Med. Microbiol. 53, 1177-1182.

(17) Scott, A. E., Burtnick, M. N., Stokes, M. G. M., Whelan, A. O., Williamson, E. D., Atkins, T. P., Prior, J. L., and Brett, P. J. (2014) Burkholderia pseudomallei capsular polysaccharide conjugates provide protection against acute melioidosis. Infect. Immun. 82, 3206-3213.

(18) Burtnick, M. N., Heiss, C., Roberts, R. A., Schweizer, H. P., Azadi, P., and Brett, P. J. (2012) Development of capsular polysaccharide-based glycoconjugates for immunization against melioidosis and glanders. Front. Cell. Infect. Microbiol. 2, 108.

(19) Heiss, C., Burtnick, M. N., Wang, Z., Azadi, P., and Brett, P. J. (2012) Structural analysis of capsular polysaccharides expressed by Burkholderia mallei and Burkholderia pseudomallei. Carbohydr. Res. 349, 90-94.

(20) Aubry, S., Sasaki, K., Sharma, I., and Crich, D. (2011) Influence of Protecting Groups on the Reactivity and Selectivity of Glycosylation: Chemistry of the 4,6-O-Benzylidene Protected Mannopyranosyl Donors and Related Species, in Reactivity Tuning in Oligosaccharide Assembly (Fraser-Reid, B., and Cristóbal López, J., Eds.) pp 141-188, Springer, Berlin Heidelberg.

(21) Aussedat, B., Vohra, Y., Park, P. K., Fernández-Tejada, A., Alam, S. M., Dennison, S. M., Jaeger, F. H., Anasti, K., Stewart, S., Blinn, J. H., et al. (2013) Chemical Synthesis of Highly Congested gp120 V1V2 N-Glycopeptide Antigens for Potential HIV-1-Directed Vaccines. J. Am. Chem. Soc. 135, 13113-13120.

(22) Heuckendorff, M., Bols, P. S., Barry, C. B., Frihed, T. G., Pedersen, C. M., and Bols, M. (2015) $\beta$-Mannosylation with 4, 6benzylidene protected mannosyl donors without preactivation. Chem. Commun. 51, 13283-13285.

(23) Marchetti, R., Dillon, M. J., Burtnick, M. N., Hubbard, M. A. Kenfack, M. T., Blériot, Y., Gauthier, C., Brett, P. J., AuCoin, D. P., and Lanzetta, R. (2015) Burkholderia pseudomallei capsular polysaccharide recognition by a monoclonal antibody reveals key details toward a biodefense vaccine and diagnostics against melioidosis. ACS Chem. Biol. 10, 2295-2302.

(24) Tamigney Kenfack, M., Blériot, Y., and Gauthier, C. (2014) Intramolecular Aglycon Delivery Enables the Synthesis of 6-Deoxy- $\beta$ d-manno-heptosides as Fragments of Burkholderia pseudomallei and Burkholderia mallei Capsular Polysaccharide. J. Org. Chem. 79, 46154634.

(25) Kabat, E. A. (1960) The Upper Limit for the Size of the Human Antidextran Combining Site. J. Immunol. 84, 82-85.

(26) Pozsgay, V. (2008) Recent Developments in Synthetic Oligosaccharide-Based Bacterial Vaccines. Curr. Top. Med. Chem. 8, $126-140$.

(27) Barresi, F., and Hindsgaul, O. (1991) Synthesis of $\beta$ mannopyranosides by intramolecular aglycon delivery. J. Am. Chem. Soc. 113, 9376-9377.

(28) Gannedi, V., Ali, A., Singh, P. P., and Vishwakarma, R. A. (2014) Intramolecular aglycon delivery for $(1 \rightarrow 2)-\beta$-mannosylation: towards the synthesis of phospholipomannan of Candida albicans. Tetrahedron Lett. 55, 2945-2947.

(29) Ishiwata, A., and Ito, Y. (2011) Synthesis of docosasaccharide arabinan motif of mycobacterial cell wall. J. Am. Chem. Soc. 133, 22752291.

(30) Nitz, M., and Bundle, D. R. (2001) Synthesis of di-to hexasaccharide 1,2 -linked $\beta$-mannopyranan oligomers, a terminal $\mathrm{S}$ linked tetrasaccharide congener and the corresponding BSA glycoconjugates. J. Org. Chem. 66, 8411-8423.
(31) Lichtenthaler, F. W., and Schneider-Adams, T. (1994) 3, 4, 6Tri-O-benzyl-. alpha.-D-arabino-hexopyranos-2-ulosyl Bromide: A Versatile Glycosyl Donor for the Efficient Generation of. beta.-DMannopyranosidic Linkages. J. Org. Chem. 59, 6728-6734.

(32) Danieli, E., Proietti, D., Brogioni, G., Romano, M. R., Cappelletti, E., Tontini, M., Berti, F., Lay, L., Costantino, P., and Adamo, R. (2012) Synthesis of Staphylococcus aureus type 5 capsular polysaccharide repeating unit using novel L-FucNAc and D-FucNAc synthons and immunochemical evaluation. Bioorg. Med. Chem. 20, 6403-6415.

(33) Yu, H., Williams, D. L., and Ensley, H. E. (2005) 4-Acetoxy-2,2dimethylbutanoate: a useful carbohydrate protecting group for the

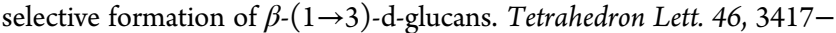
3421.

(34) Unverzagt, C., Eller, S., Mezzato, S., and Schuberth, R. (2008) A Double Regio- and Stereoselective Glycosylation Strategy for the Synthesis of N-Glycans. Chem. - Eur. J. 14, 1304-1311.

(35) Lee, H.-K., Scanlan, C. N., Huang, C.-Y., Chang, A. Y., Calarese, D. A., Dwek, R. A., Rudd, P. M., Burton, D. R., Wilson, I. A., and Wong, C.-H. (2004) Reactivity-Based One-Pot Synthesis of Oligomannoses: Defining Antigens Recognized by 2G12, a Broadly Neutralizing Anti-HIV-1 Antibody. Angew. Chem., Int. Ed. 43, 10001003.

(36) Iino, K., Iwamoto, S., Kasahara, Y., Matsuda, K., Tonozuka, T., Nishikawa, A., Ito, Y., and Matsuo, I. (2012) Facile construction of 1,2cis glucosidic linkage using sequential oxidation-reduction route for synthesis of an ER processing $\alpha$-glucosidase I substrate. Tetrahedron Lett. 53, 4452-4456.

(37) Fürstner, A., and Konetzki, I. (1998) Total Synthesis of Caloporoside. J. Org. Chem. 63, 3072-3080.

(38) Campbell, A., and Plante, O. (2015) Synthetic oligosaccharides for Pseudomonas aeruginosa vaccine. PCT Int. Appl. WO 2015002954.

(39) Meyer, S. D., and Schreiber, S. L. (1994) Acceleration of the Dess-Martin Oxidation by Water. J. Org. Chem. 59, 7549-7552.

(40) Bock, K., and Pedersen, C. (1974) A study of $13 \mathrm{CH}$ coupling constants in hexopyranoses. J. Chem. Soc., Perkin Trans. 2 2, 293-297.

(41) Xu, Y.-C., Bizuneh, A., and Walker, C. (1996) A Reagent for Selective Deprotection of Alkyl Acetates. J. Org. Chem. 61, 9086-9089.

(42) Seeberger, P. H., Soucy, R. L., Kwon, Y.-U., Snyder, D. A., and Kanemitsu, T. (2004) A convergent, versatile route to two synthetic conjugate anti-toxin malaria vaccines. Chem. Commun., 1706-1707.

(43) Chauvin, A.-L., Nepogodiev, S. A., and Field, R. A. (2005) Synthesis of a 2,3,4-Triglycosylated Rhamnoside Fragment of Rhamnogalacturonan-II Side Chain A Using a Late Stage Oxidation Approach. J. Org. Chem. 70, 960-966.

(44) Pinto, B. M., Morissette, D. G., and Bundle, D. R. (1987) Synthesis of oligosaccharides corresponding to biological repeating units of Shigella flexneri variant Y polysaccharide. Part 1. Overall strategy, synthesis of a key trisaccharide intermediate, and synthesis of a pentasaccharide. J. Chem. Soc., Perkin Trans. 1 1, 9-14.

(45) Iversen, T., and Bundle, D. R. (1981) Benzyl trichloroacetimidate, a versatile reagent for acid-catalysed benzylation of hydroxygroups. J. Chem. Soc., Chem. Commun., 1240-1241.

(46) Mond, J. J., Lees, A., and Snapper, C. M. (1995) T CellIndependent Antigens Type 2. Annu. Rev. Immunol. 13, 655-692.

(47) Snapper, C. M., and Mond, J. J. (1996) A model for induction of $\mathrm{T}$ cell-independent humoral immunity in response to polysaccharide antigens. J. Immunol. 157, 2229-33.

(48) Weintraub, A. (2003) Immunology of bacterial polysaccharide antigens. Carbohydr. Res. 338, 2539-2547.

(49) Stein, K. E. (1992) Thymus-Independent and ThymusDependent Responses to Polysaccharide Antigens. J. Infect. Dis. 165, S49-S52.

(50) Adamo, R., Nilo, A., Castagner, B., Boutureira, O., Berti, F., and Bernardes, G. J. L. (2013) Synthetically defined glycoprotein vaccines: current status and future directions. Chemical Science 4, 2995-3008.

(51) Bromuro, C., Romano, M., Chiani, P., Berti, F., Tontini, M., Proietti, D., Mori, E., Torosantucci, A., Costantino, P., Rappuoli, R. 
et al. (2010) Beta-glucan-CRM197 conjugates as candidates antifungal vaccines. Vaccine 28, 2615-2623.

(52) Warawa, J. M. (2010) Evaluation of surrogate animal models of melioidosis. Front. Microbiol. 1, 10.3389/fmicb.2010.00141

(53) Titball, R. W., Russell, P., Cuccui, J., Easton, A., Haque, A., Atkins, T., Sarkar-Tyson, M., Harley, V., Wren, B., and Bancroft, G. J. (2008) Burkholderia pseudomallei: animal models of infection. Trans. $R$. Soc. Trop. Med. Hyg. 102, S111-S116.

(54) Scott, A. E., Laws, T. R., D’Elia, R. V., Stokes, M. G. M., Nandi, T., Williamson, E. D., Tan, P., Prior, J. L., and Atkins, T. P. (2013) Protection against experimental melioidosis following immunisation with live Burkholderia thailandensis expressing manno-heptose capsule. Clinical and Vaccine Immunology 20, 1041.

(55) Fernandez, C., and Sverremark, E. (1994) Immune Responses to Bacterial Polysaccharides: Terminal Epitopes Are More Immunogenic Than Internal Structures. Cell. Immunol. 153, 67-78.

(56) Lu, Z., Rynkiewicz, M. J., Yang, C.-Y., Madico, G., Perkins, H. M., Wang, Q., Costello, C. E., Zaia, J., Seaton, B. A., and Sharon, J. (2013) The binding sites of monoclonal antibodies to the nonreducing end of Francisella tularensis $\mathrm{O}$-antigen accommodate mainly the terminal saccharide. Immunology 140, 374-389.

(57) Sinha, K., Box, M., Lalli, G., Schiavo, G., Schneider, H., Groves, M., Siligardi, G., and Fairweather, N. (2000) Analysis of mutants of tetanus toxin HC fragment: ganglioside binding, cell binding and retrograde axonal transport properties. Mol. Microbiol. 37, 1041-1051. (58) Scott, A. E., Ngugi, S. A., Laws, T. R., Corser, D., Lonsdale, C. L., D'Elia, R. V., Titball, R. W., Williamson, E. D., Atkins, T. P., and Prior, J. L. (2014) Protection against Experimental Melioidosis following Immunisation with a Lipopolysaccharide-Protein Conjugate. J. Immunol. Res. 2014, 392170.

(59) Holden, M. T. G., Titball, R. W., Peacock, S. J., CerdeñoTárraga, A. M., Atkins, T., Crossman, L. C., Pitt, T., Churcher, C., Mungall, K., Bentley, S. D., et al. (2004) Genomic plasticity of the causative agent of melioidosis. Proc. Natl. Acad. Sci. U. S. A. 101, $14240-14245$.

(60) Godoy, D., Randle, G., Simpson, A. J., Aanensen, D. M., Pitt, T. L., Kinoshita, R., and Spratt, B. G. (2003) Multilocus Sequence Typing and Evolutionary Relationships among the Causative Agents of Melioidosis and Glanders, Burkholderia pseudomallei and Burkholderia mallei. Journal of Clinical Microbiology 41, 2068-2079.

(61) Champion, O. L., Gourlay, L. J., Scott, A. E., Lassaux, P., Conejero, L., Perletti, L., Hemsley, C., Prior, J., Bancroft, G., and Bolognesi, M. (2016) Immunisation with proteins expressed during chronic murine melioidosis provides enhanced protection against disease. Vaccine 34, 1665. 